\title{
Investigation of the Oxidation Behavior of Soot in Diesel Particle Filter structures
}

\section{Panayotis Dimopoulos Eggenschwiler and Daniel Schreiber \\ EMPA}

CITATION: Dimopoulos Eggenschwiler, P. and Schreiber, D., "Investigation of the Oxidation Behavior of Soot in Diesel Particle Filter structures," SAE Technical Paper 2015-24-2516, 2015, doi:10.4271/2015-24-2516.

Copyright (C) 2015 SAE International

\begin{abstract}
Particulate matter in diesel exhaust is captured in diesel particulate filters (DPFs). Since increased load in the filter and thus increased pressure drop deteriorates the engine performance, the filter load of the DPF has to be removed during a process referred to as regeneration. Measures for successful regeneration aim at accelerating soot oxidation and increase fuel consumption. Regeneration lay-out and thus fuel consumption increase is strongly depending on the oxidation behavior of soot.
\end{abstract}

The aim of the present study is the investigation of soot oxidation characteristics. Therefore particle filters have been loaded with soot using the exhaust gas of small heavy duty vehicle operated under defined conditions on an engine dynamometer. The particle filters have been then dismantled and fragmented on their constituting segments. Each filter segment has been regenerated individually in a specifically designed test bench. Heated gas of constant temperature has been induced through the segments. Based on the species balances measured, soot oxidation rates have been computed. In parallel, a scale with milligram resolution recorded the time evolution of the segment weight.

Based on the soot oxidation rates characteristic kinetic parameters have been computed. Regeneration progress has been approached by a simple Arrhenius, a shrinking core and a random pore size distribution growth model. The influence of two different oxygen levels in the feed gas has been investigated. Soot regeneration characteristics in segments from the filter core have been similar exhibiting rather low activation energies of around $50 \mathrm{~kJ} / \mathrm{mol}$. Soot in filter segments located in the periphery had substantially higher activation energies, $80 \mathrm{~kJ} / \mathrm{mol}$. This different behavior is attributed to the lower temperatures of the filter periphery during the loading procedure and differences in the soot structure and composition.

\section{Introduction}

Diesel particulate matter (PM) can be removed from the exhaust streams by means of filtration using Diesel Particulate Filters (DPF). The filtered soot has periodically to be removed from the filter during a process commonly known as 'regeneration' in order to avoid a series of implications deteriorating engine operation characteristics.

Regeneration of the filtered soot mainly occurs via oxidation processes. Conditions typical for diesel exhaust are not very favorable for oxidation. Although there is no lack of oxygen, the low temperatures prevailing, mainly attributable to the high energy conversion efficiency of diesel engines, impose a critical impediment. In order to regenerate particulate filters, the loaded soot can be oxidized by the exhaust gas components $\mathrm{O}_{2}$ and $\mathrm{NO}_{2}$. The filter regeneration only with $\mathrm{O}_{2}$ requires high temperatures, above $550^{\circ} \mathrm{C}$, in order to oxidize the stored soot within acceptable times, a process often referred to as active regeneration. Due to the high $\mathrm{O}_{2}$ concentration, the resulting reaction rates can be much higher than those obtained by $\mathrm{NO}_{2}$, which, on the other hand, can be used for soot oxidation at lower temperatures, above $250^{\circ} \mathrm{C}$, often called passive regeneration.

During active regeneration engine combustion is retarded in order to increase exhaust gas temperature. In parallel throttling of the intake air leads to fuel rich and thus partly incomplete in-cylinder combustion. The result is an extremely high amount of unburned hydrocarbons and CO reaching the Diesel Oxidation Catalyst (DOC). The exothermal oxidation reaction in the DOC in combination with the increased engine-out temperature by the late combustion lead to the high temperatures necessary for soot oxidation. Self-explanatory, that all the mentioned measures increase substantially fuel consumption. Apart from that, active regeneration can get out of control and damage the filter. It is obvious, that understanding the oxidation rates of soot in the DPF is essential for determining active regeneration strategies, minimizing the fuel consumption impact and improving reliability of the system. 
A series of works have studied particle oxidation behaviour, most of them under controlled environment of either temperature programmed oxidation (TPO), and /or thermogravimetric analysis (TGA) $[\underline{1}, \underline{2}, \underline{3}, \underline{4}, \underline{5}]$.

Following a very careful approach, [1] , delivered kinetic parameters describing the oxidation and gasification of model and real diesel soot over a wide range of experimental conditions relevant for diesel engine exhaust particulates. They have shown, that the overall process can be described by a linear combination of oxidant-specific pseudo-first-order rate coefficients. The activation energies obtained with $10 \% \mathrm{O} 2$ concentration in the feed gas have been about $100 \mathrm{~kJ} /$ mol rather lower than from other studies, $[\underline{2}, \underline{3}, \underline{4}, \underline{5}, \underline{6}]$. It could be also found that the presence of water vapour increased the particle oxidation rates although the increase was not affected by changes in the vapour concentration.

A further series of works has studied the influence of particulate composition and nanostructure (nanometer and subnanometer scales) as well as of the primary particles and agglomerate sizes on the reactivity $[\underline{7}, \underline{8}, \underline{9}, \underline{10}, \underline{11}, \underline{12}, \underline{13}, \underline{14}, \underline{15}]$. The term nanostructure refers to the dimensions, relative orientation and curvature of the graphene layer segments. The relative number and accessibility of potential reactive carbon layer edge sites can be described by nanostructure. It has been shown that these sites are potentially accessible for H-atom abstraction. Longer carbon lamella planes (larger crystallites) result in fewer reactive edge sites. Geometrically, carbon atoms in edge sites are more accessible to oxygen chemisorption and may form bonds though unpaired $\mathrm{sp}^{2}$ electrons, [15]. Carbon atoms in basal planes have only shared $\pi$ electrons accessible to bond formation. Consequently, the observed reactivity will be an average of basal vs. edge site carbon atom reactivities for graphitic layer planes of finite dimensions, [15]. HRTEM has become the preferred approach for characterizing nanostructure of carbons due to the fact that the major parameters such as fringe length, separation distance, orientation ordering and tortuosity are clearly observable.

According to $[\underline{1}, \underline{2}]$ the oxidation rate of carbonaceous materials can be described using the general kinetic model equation:

$$
\frac{d m_{s}}{d t}=N_{T} \cdot A \cdot e^{-\frac{E_{A}}{R T}} \cdot f\left(p_{\mathrm{O}_{2}}, p_{\mathrm{H}_{2} \mathrm{O}}, p_{\mathrm{NO}_{2}}, \ldots\right)
$$

Where $\mathrm{N}_{\mathrm{T}}$ is the total number of active carbon sites, A the Arrhenius pre-exponential factor, $\mathrm{E}_{\mathrm{A}}$ the activation energy, $\mathrm{R}$ the universal gas constant and $\mathrm{f}\left(\mathrm{p}_{\mathrm{O} 2}, \mathrm{p}_{\mathrm{H} 2 \mathrm{O}}, \ldots\right)$ is a function which describes the dependency of the reaction rate on the partial pressure of various gas components. The influence of the gas partial pressures is often limited to a linear influence of the oxygen partial pressure, $[\underline{2}, \underline{13}, \underline{16}]$.

For the determination of the total number of carbon active sites, $\mathrm{N}_{\mathrm{T}}$, several different approaches have been followed. [13] suggests relating $\mathrm{N}_{\mathrm{T}}$ to an active site concentration and to the soot surface. While the former may be somehow constant over the regeneration, the determination of the latter requires knowledge of the regeneration evolution. Here several approaches have been followed, based on geometrical reasoning, [17], BET (Brunauer-Emmett-Teller surface measurement technique based on physical adsorption of gas molecules on a solid surface) soot surface measurements, [두] , as well as using micro- and nanostructural aspects of the soot primary particles and agglomerates, $[\underline{9}, \underline{10}, \underline{11}, \underline{12}]$.

Concerning the magnitude as well as the dependencies of the activation energy, $\mathrm{E}_{\mathrm{A}}$, and the pre-exponential factor, $\mathrm{A}$, for $\mathrm{PM}$ oxidation there is substantial controversy in the literature. Activation energies varying from $38 \mathrm{~kJ} / \mathrm{kmol}$ to $168 \mathrm{~kJ} / \mathrm{kmol}$ can be found for thermal oxidation of PM, [16]. Dependencies of the activation energy from the PM composition, [ 6 ], the PM amount available for oxidation, $[\underline{6}, \underline{16}]$, the prevailing temperature $[\underline{6}, \underline{16}]$, the DPF material, [18], and the catalytic coating of the DPF, [20, 21] have been investigated. However, the results are difficult to compare since all the mentioned dependencies have to be taken into account and different conditions prevailed in the studies, at least those, we are aware of. In addition some of the reported results are ambiguous for not saying contradictory (example, the activation energies reported for catalytically coated filters are sometimes higher than those reported by other researchers for uncoated filters).

There seems to be some agreement, concerning the initial phase of soot oxidation where rapidly changing reactivity is reported. This initial phase is associated with roughly $10-25 \%$ of the carbon available mass, $[\underline{5}, \underline{16}]$. The associated activation energies are low. A number of studies have shown that the initial stages of combustion display anomalously high combustion rates $[\underline{2}, \underline{5}]$, which has been attributed to the removal of absorbed hydrocarbons (SOF). Analysis of soot oxidation behavior after this initial phase has resulted in substantially higher activation energies. The activation energies show also some dependency on the soot amount available for oxidation. [ $\underline{2}$ and $\underline{5}$ ] report low activation energies in combination with low soot quantities available, with more available soot the activation energies increase. Should though, the available soot be substantially more (to our knowledge, no exact thresholds have been reported) the activation energy decreases. Finally, in [18] differences in activation energies have been attributed to different conditions of the in-cylinder combustion. Even more complex is the discussion concerning the pre-exponential factor, A. The above described dependencies of the reported activation energies are similar for the pre-exponential factors. The reported values, though differ sometimes by orders of magnitude.

Recently, some criticisms was also expressed concerning the interpretation of TPO and TGA results. Under certain conditions, (such as low reactant gas flow rate, high sample mass etc.) oxygen diffusion, both external, to reach the sample surface, and internal, inside the porous soot layer can complex interpretation concerning the reaction kinetics $[\underline{15}, \underline{19}]$.

In a previous work, [22] we have analyzed the active regeneration process on a vehicle. The varying engine operational settings over the regeneration did not allow kinetic analysis in detail. A specifically build test rig allowing more detailed analysis was built. The aim is to analyze particulate oxidation behavior under stable conditions which are nearest possible to the real engine and aftertreatment systems environment. Specific attention was given in the lay-out of the test rig in order to perform particle oxidation experiments having the particle characteristics like composition, surface and structure as near to the real engine setup as possible. 


\section{Experimental Setup and Evaluations}

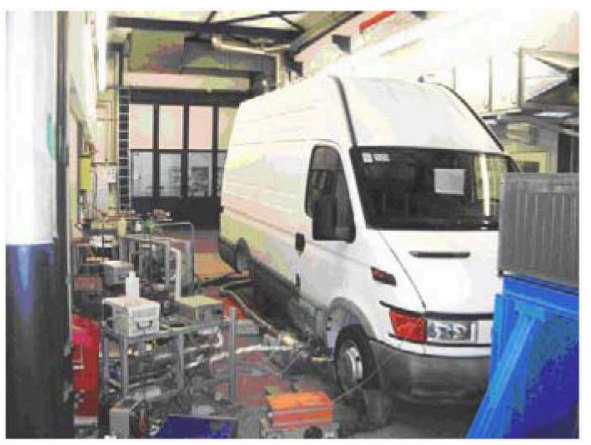

Figure 1. Small heavy duty truck on the chassis dynamometer
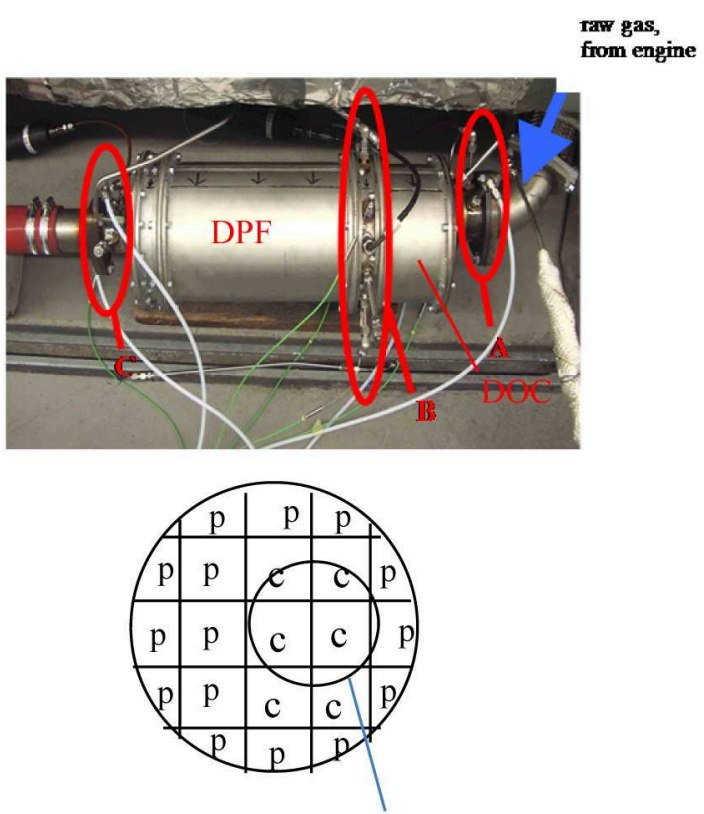

Exhaust gas feeding pipe from the engine

Figure 2. Aftertreatment system and instrumentation. Schematic showing DPF cross section location of the exhaust gas feeding pipe together with the DPF segments considered as central (c) and peripheral (p).

Diesel Particulate Filters (DPFs) have been loaded with particles on a chassis dynamometer as can be seen in Fig. 1. The vehicle used for the experiments is an Iveco Daily equipped with a 2.3-litre 4 cylinder (F1A) common rail diesel with turbocharger. In place of the original DOC-DPF system a specially manufactured DOC-DPF casing was used in order to enable easy exchanges and monitor all relevant parameters, Fig. 2. The casing was positioned approx. $0.5 \mathrm{~m}$ further apart from the engine in respect to the original aftertreatment system position. It is important to note that the pipe feeding the exhaust gases to the exhaust aftertreatment device was mounted eccentrically, as can be seen in Fig. 2 .

The used DPFs have been SiC-DPFs without any catalytic coating. Their dimensions were: $168 \mathrm{~mm}$ diameter and $280 \mathrm{~mm}$ length, which translates to a total volume of $6.21 \mathrm{t}$ for the entire DPF. The channel density was $200 \mathrm{cpsi}$, hence each square channel had $1.5 \mathrm{~mm}$ by $1.5 \mathrm{~mm}$ opening section. The entire filter comprised of 25 segments, 9 whole segments in the central area, while the remaining 16 in the periphery, some of them apportioned. The central segments were directly fed by the incoming exhaust gases through the eccentric positioned pipe. Peripheral segments had indirect and, at least to some extent, less exhaust gas supply based on the eccentirc assembly as shown on Figs 1 and $\underline{2}$. Each whole segment had a square cross section of $33 \mathrm{~mm} \times 33 \mathrm{~mm}$ and integrated $18 \times 18$ channels. The average thickness of the walls between the channels was $0.35 \mathrm{~mm}$.

The filter loading was performed at one specifically chosen engine load and speed point in order to achieve a significant particle loading in the filter at an acceptable time. This engine operation point is characterized by sufficient particle emission in combination with relative low temperatures at the engine exhaust. By using only one engine operation point for the present investigations, inherent variations of particle and soot microstructure has been avoided. Of particular interest is that at this chosen engine point the exhaust gas temperature was $545 \mathrm{~K}$ at the DPF center and good $30 \mathrm{~K}$ lower at the DPF periphery. Whether this difference, at these relatively low exhaust temperatures, has an influence on the particle oxidation behavior will be discussed in the results and discussion section. In order to assure that at least all entire segments collected enough particles for the subsequent regeneration experiments, loading was continued until roughly $10 \mathrm{~g} / \mathrm{lt}$ of particles have been collected in the entire DPF. The corresponding amount of particles collected in each (whole) segment has been around $5 \mathrm{~g}$.

After particle loading the DPFs have been dismounted and partitioned in their constituting segments. Then each segment has been regenerated individually in a specifically build test rig. A schematic of this test rig can be found in the Appendix. In the rig, each DPF segment was fixed and sealed with intumescent mat in an insulated reactor tube. The segment was heated with an electrical heating wire, which was attached to the segment body within the reactor tube. The purpose of the heating was to assure similar temperature in all channels of the segment and to minimize heat losses to the environment during regeneration.

Upstream of the reactor, an electrical gas heater was mounted in order to heat the inlet gas to $773 \mathrm{~K}$. A mixing element for mixing the exhaust gas from the channels, and a constant flow dilution system were mounted downstream of the DPF segment. The diluted cooled exhaust gas was aspirated with a vacuum suction pump. A gas analyzer supplemented with a flow meter, a temperature and a pressure sensor was connected to the cooled, diluted exhaust gas to calculate the wet total mass-flow and the dry mass-flow of oxygen, carbon monoxide and carbon dioxide. With a three-way valve the gas analyzer could be switched to measure diluted or undiluted exhaust gas in order to estimate the dilution. Gas analyzer data have been collected with $1 \mathrm{~Hz}$ temporal resolution.

Gas temperatures are measured at the DPF-segment inlet, T2, downstream the mixing-element, T4, and downstream the constant flow dilution. An additional temperature was measured in an outlet-channel, T3. The thermocouple was inserted in an outletchannel and positioned near the segment center.

The entire segment assembly was positioned on a balance with $1 \mathrm{mg}$ resolution in order to follow the weight change of the segment during regeneration.

This setup led to segment regenerations where the GHSV have been around $20^{\prime} 000 \mathrm{~h}^{-1}$. 
The gas analyser outputs of the $\mathrm{CO}$ and $\mathrm{CO} 2$ concentrations at the segment exit have been used for computing the particle mass oxidized during each time step. Based on these results carbon mass-based pseudo-first-order reaction rates (according to [1] ) have been obtained:

$$
\frac{d m_{s}}{m_{s} d t}=k_{m}
$$

In the present work the pseudo-first order reaction rate $\mathrm{k}_{\mathrm{m}}$ was further analysed by estimating the parameters and or the fit of the three following models:

$$
k_{m}=p_{O_{2}}^{n} A \cdot e^{-\frac{E_{A}}{R T}}
$$

Here, values for the pre-exponential factor, A, and the activation energy $\mathrm{E}_{\mathrm{A}}$ have been derived as described in the results and discussion section. The dependence of $\mathrm{k}_{\mathrm{m}}$ on oxygen partial pressure is also a widely discussed item. In the present work $n=1$ was chosen for all evaluations.

According to the shrinking core model, the ratio of the initial to the residual surface to volume ratio can be obtained by considering the particles as shrinking ideal spheres. Thus in the shrinking core model $\mathrm{k}_{\mathrm{m}}$ can be expressed according to [1] as:

$$
k_{m}=p_{O_{2}}^{n} A \cdot e^{-\frac{E_{A}}{R T}} \cdot S_{0}\left(1-\xi_{m}\right)^{-\frac{1}{3}}
$$

Where $\mathrm{S}_{\mathrm{o}}$ is the initial surface area and $\xi_{\mathrm{m}}$ the percentage of particle mass oxidized. With increasing conversion this model predicts steady increase of the surface to volume ratio and thus $\mathrm{k}_{\mathrm{m}}$. However, propagating oxidation may also lead to a decline, since smaller particles are first and faster to oxidize. Taking such cases into account may require a different model as proposed by [4] referred to in this work as the Bhatia and Perlmutter model:

$$
k_{m}=p_{O_{2}}^{n} A \cdot e^{-\frac{E_{A}}{R T}} \cdot S_{0}\left(1-\xi_{m}\right) \sqrt{1-\psi \ln \left(1-\xi_{m}\right)}
$$

This model is based on the growth of pores with random pore size distribution. At low $\xi_{\mathrm{m}}$ the surface is increasing while at higher values the surface decreases. $\psi$ is a structural factor that determines the location of this reversal.

\section{Results and Discussion}

\section{Regeneration of a Typical Segment from the Periphery of the DPF}

Figure 3 shows the main part of the time history of a typical DPF segment regeneration. It is worth to note that the features shown in $\underline{\text { Figs. } 3}, \underline{4}, \underline{5}, \underline{6}, \underline{7}, \underline{8}, \underline{9}, \underline{10}, \underline{11}$ all belong to a regeneration of a segment from the filter periphery. In addition, the regeneration described in these figures has been performed with heated dry air as a feed gas to the segment, having $21 \%$ of $\mathrm{O}_{2}$ and practically no water.

The gases fed to the segment are heated to a set-point temperature of $773 \mathrm{~K}$ (temperature T2). Thereafter the heating is controlled for maintaining this temperature at the segment entrance. T3 shows the temperature inside an outflow channel of the segment. Initially, while $\mathrm{t}<1750$ s, T2 is higher than T3 and the feeding gases heat up the segment. In parallel, particle oxidation starts and accelerates over time leading to increasing heat release and increasing $\mathrm{T} 3$. The rise of $\mathrm{T} 3$ is accelerated until a maximum has been reached at roughly 1050K. Thereafter T3 decreases with a moderate rate.

The temperature at the segment exit, T4, is always lower than inside the channel, T3, due to heat losses to the environment and local cooling. This is clear indication that the temperature characteristic for the soot inside the channel is T3.

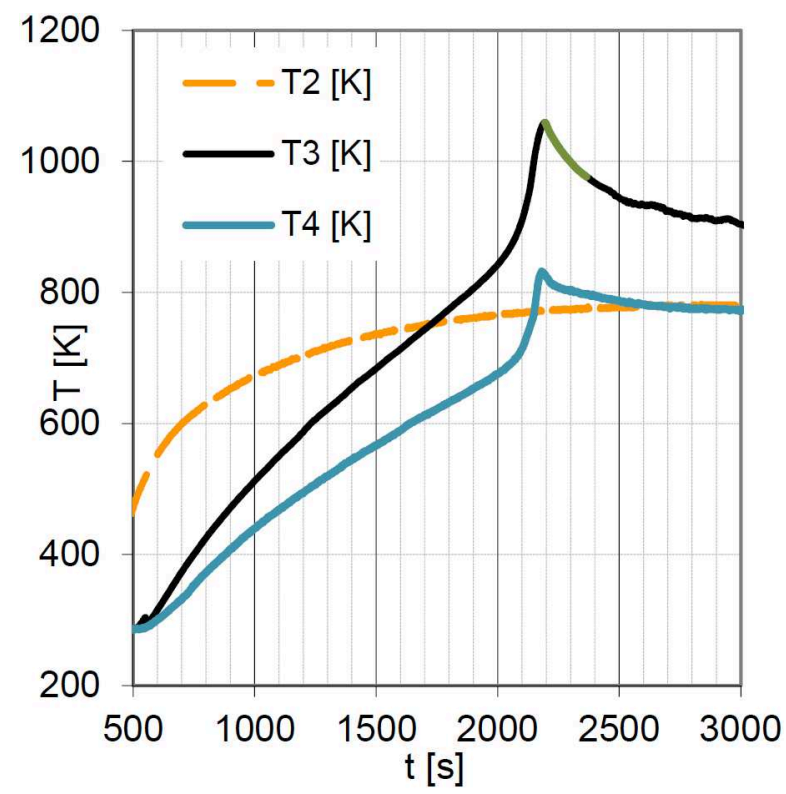

Figure 3. Typical temperature time history during the regeneration of a DPF segment.

The composition of the gases exiting the segment during regeneration is shown in Fig. 4. Increase of $\mathrm{CO}$ and $\mathrm{CO}_{2}$ in the exit evidences particle oxidation. The first $\mathrm{CO}$ and $\mathrm{CO}_{2}$ traces in the segment exit have been measured at about $\mathrm{t}=600 \mathrm{~s}$, while the temperature of the gases at the segment entrance have been roughly $600 \mathrm{~K}$. Most likely, desorption and oxidation of hydrocarbons and volatiles components, [1], from the particle cake in the filter, are the sources of the initial $\mathrm{CO}$ and $\mathrm{CO}_{2}$ emissions. Later, the $\mathrm{CO}$ and $\mathrm{CO}_{2}$ content in the segment exit increase sharply. Interestingly, almost over the entire regeneration the ratio of $\mathrm{CO}_{2}$ to $\mathrm{CO}$ remains constant around 3:1. Also plotted in Fig. 4 is the oxygen concentration in the segment exit, providing evidence of global abundance of oxygen during the entire regeneration. 


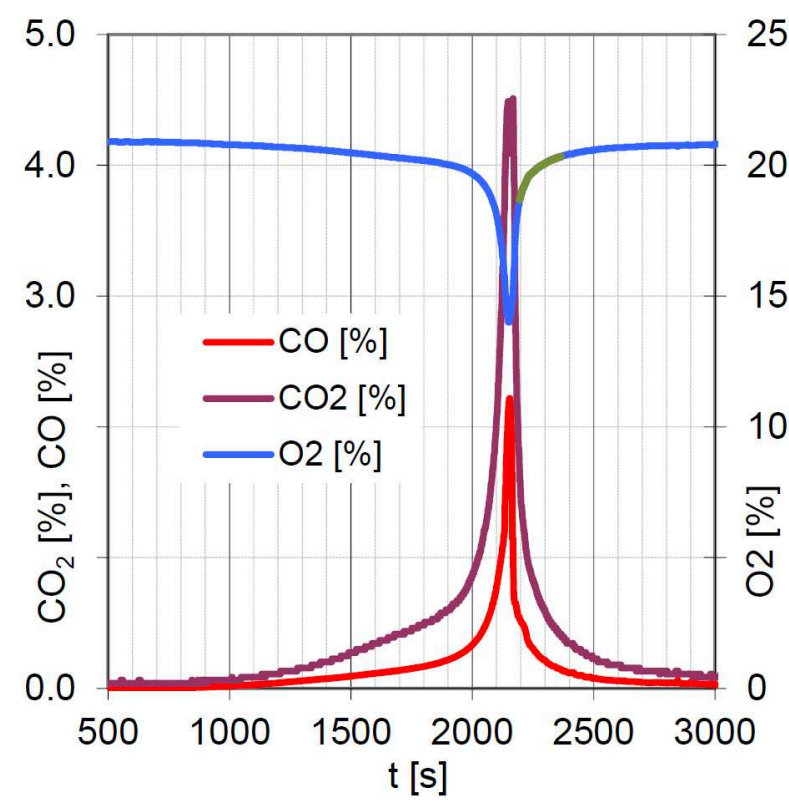

Figure 4. Gas analysis results at the segment exit during regeneration.

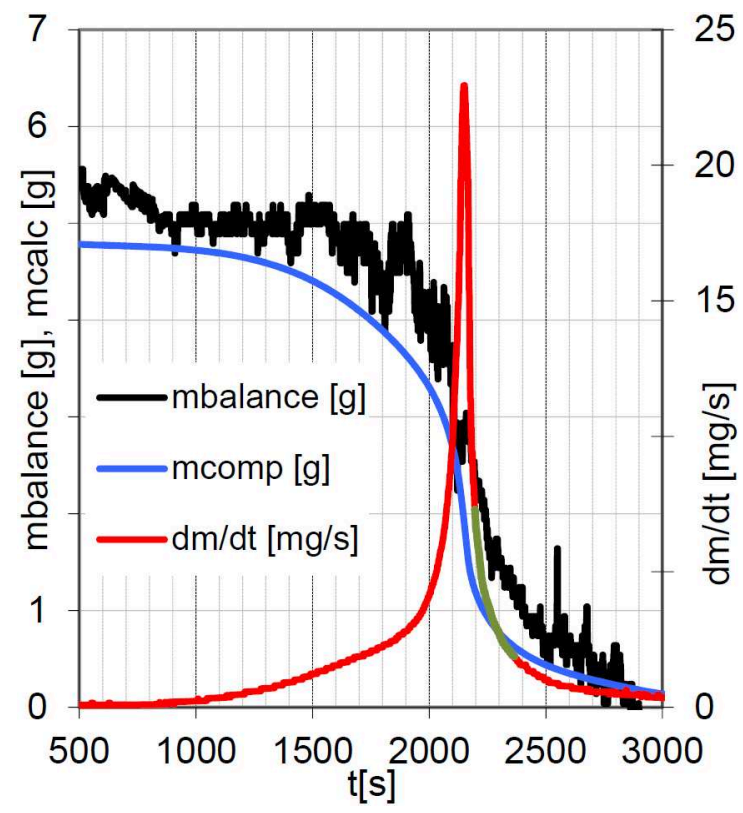

Figure 5. Oxidized particle mass and oxidation rate computed from the sum of carbon oxide signals at the segment exit in comparison to the segment weight.

The $\mathrm{CO}$ and $\mathrm{CO} 2$ concentrations have been used for computing the particle mass oxidized in each time step. Similarly, the particle mass oxidation rate has also been obtained. In a first phase, the mass of the particles oxidized increases slowly (fig. 5). Then a sharp increase follows. This increase leads to a maximum at rates of around $20 \mathrm{mg} / \mathrm{s}$. Thereafter the oxidized mass decreases. The computed mass of oxidized particles is in an acceptable agreement with the weight change of the segment over the regeneration as evidenced by the balance data also show in fig. 5 .

For deeper insights, $\underline{\text { figs. } 6}$ and $\underline{7}$ provide the evolution of the pseudo-first order reaction rate coefficient, $\mathrm{k}_{\mathrm{m}}$, computed from the measured data according to Eg. (1) and the particle mass conversion, $\xi_{\mathrm{m}}$, over time, (ig. 6 ) as well as over the temperature of the outflow channel, T3 (fig. 7).
Initially, the pseudo-first order reaction rate coefficient, $\mathrm{k}_{\mathrm{m}}$, increases almost linearly with temperature $\mathrm{T} 3$ until roughly $800 \mathrm{~K}$ have been reached (fig. 7). This corresponds to the oxidation of the first $25 \%$ of the particles (fig. 7) and to the first 1900s (ig. 6) of the regeneration. The pseudo-first order reaction rate coefficients obtained in this first phase (figs 6 and $\underline{7}$ ) agree very good with those reported in [1] for similar temperatures.

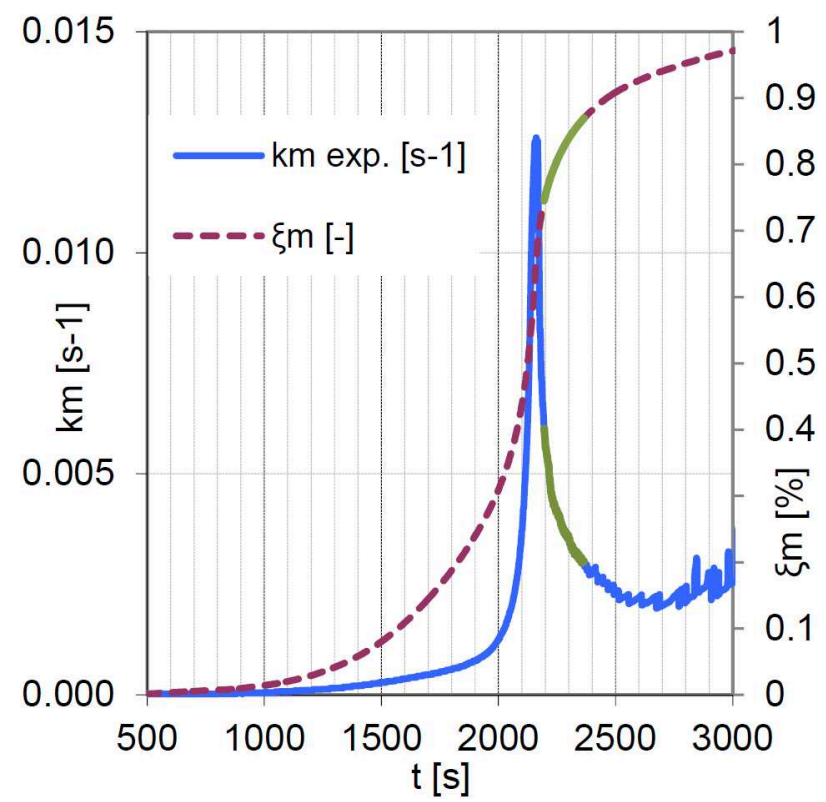

Figure 6. Time history of the pseudo-first order reaction rate coefficient, $\mathrm{k}_{\mathrm{m}}$, and particle mass conversion $\xi_{\mathrm{m}}$.

After this initial phase the temperatures as well as the reaction rates increase drastically. The rapid increase is caused by the temperature increase as well as by the increase of the reaction area, as bigger particles and parts of the particle cake collapse to smaller entities. With propagating particle oxidation, the surface to volume ratio of the particles increases, increasing the reactant accessibility to the shrinking soot particles and opening of occluded pore space. The surface increase and temperature increase effects reinforce each other and result in this rapid increase of the particle oxidation rate. This phase is labelled as phase 2 in Fig. 7. A maximum of the pseudo-first order rate reaction coefficient is reached together with the temperature maximum after oxidizing some $70 \%$ of the particle mass.

Thereafter the regeneration enters a short, third phase, as the reaction rates decrease sharply, although the temperature is still slightly increasing. The most secure explanation for this sharp decline is the collapse of the surface area available for reactions. A big amount of particles has been already oxidized and the point is reached where the remaining ones provide less surface area for reactions. The slight increase of temperature can be attributed to the thermal inertial of the entire segment.

After this collapse a fourth phase follows where the reaction rate coefficient decreases linearly with temperature. This phase is indicated with a separate color in $\underline{\text { figs }} 3, \underline{5}, \underline{6}$ and $\underline{7}$. We assume that in this phase the particle oxidation is determined only by the chemical kinetics and thus temperature. 
The last and fifth phase of the regeneration starts roughly at $\xi_{\mathrm{m}}>0.9$. Here oxidation is still ongoing but it is unstable. The remaining particle mass is too low and the incrementally oxidizing mass is even lower.

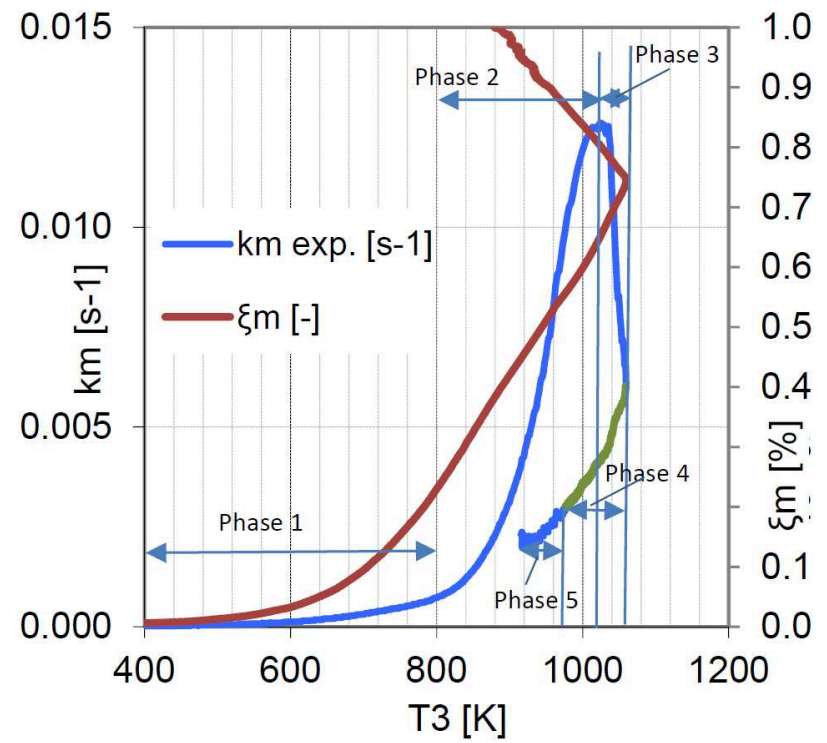

Figure 7. Pseudo-first order reaction rate coefficient $\mathrm{k}_{\mathrm{m}}$ and particle mass conversion $\xi_{\mathrm{m}}$ over temperature.

All segment regenerations performed had the same pattern of the described five phases. Depending on the segment location in the filter and the composition of the feed gas there have been variations in the length of the phases as well as in the peak oxidation rate coefficients and peak temperatures. Differences among the different segments will be discussed in a later section.

\section{Particle Oxidation Parameters During the Kinetic Limited Phase}

The start of the fourth, "kinetic controlled" oxidation phase was defined to be the point after the sharp decline where the temperature in the channel starts decreasing, figs 6 and $\underline{7}$. The length of this phase was defined either by the starting point of larger instabilities or by the point where the goodness of the linear fit, as shown in fig. 8, fell below $95 \%$. Based on these definitions the "kinetic controlled" oxidation phase starts for this segment at $\mathrm{t}=1195 \mathrm{~s}$ with $75 \%$ of the particle mass oxidized and ends at $\mathrm{t}=1365 \mathrm{~s}$, where $87 \%$ of the particle mass is oxidized (figs. 3 and $\underline{6}$ ). During this period the average particle oxidation rate was $5 \mathrm{mg} / \mathrm{s}$ (fig. 5 ).

Over this entire period a regression has been performed as indicated in fig. 8. The regression has a good fit $(>97 \%)$. The slope of the regression line corresponds to the activation energy of the oxidation reaction while the intercept corresponds to the pre-exponential factor. Strictly, these parameters can be assigned only to particulate matter which has undergone heating to these high temperatures with all structural and compositional consequences. The activation energy obtained lies at $\mathrm{E}_{\mathrm{A}}=85 \mathrm{~kJ} / \mathrm{mol}$ and the pre-exponential factor at 500 , values corresponding to the lower side of the values published in literature so far, $[\underline{1}, \underline{2}]$.

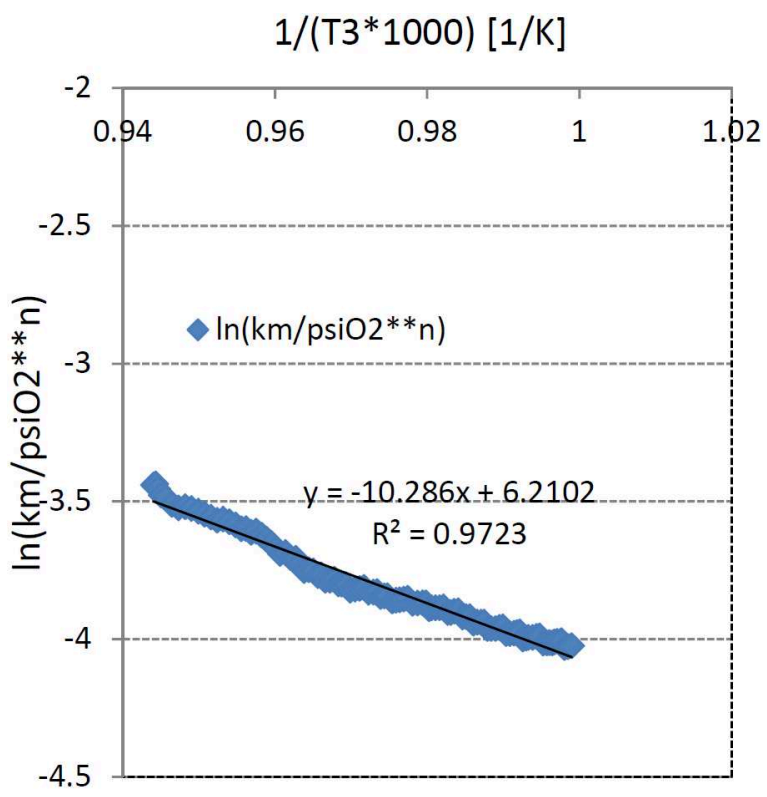

Figure 8. Linear fit of the logarithm of the reaction rate coefficient vs. the inverse temperature.

The interesting point is whether the kinetic parameters obtained by this method are able to reconstruct the entire regeneration they have been derived from.

For reconstructing the regenerations based on the derived kinetic parameters three different approaches as described by equations (2), (3) and (4) have been chosen. Figs 9 and 10 show the results.

As expected, the simple Arrhenius approach is not capable of reconstructing the rapid increase of the reaction rate during the second phase of the regeneration. Of course, the reconstruction of the fourth phase is very good in terms of the temperature dependency (fig. 9), since during this phase the parameters have been derived. Nevertheless, should this fourth phase be reconstructed in terms of the oxidized particle mass (ig. 10) the deviation from the experiment is significant. Overall the "simple Arrhenius" approach is not performing well neither in predicting the regeneration duration (fig. 10) nor its temperature dependence (fig. 9).

The shrinking core in combination with the Arrhenius model can reconstruct the second phase increase of reaction rate fairly well, taking into account dependence from the oxidized particle mass (fig. 10). The temperature dependence of the reaction rate during this second phase is poorly reconstructed (fig. 9). Thus, this model does not account correctly for the surface increase. In addition, the collapse and the fourth phase of the regeneration are even less accurately reconstructed. This is also not surprising since this model is only accounting for surface to volume ratio increase. The decrease of the reaction rate is only due to the decrease of temperature.

Best results have been obtained by the combination of the Arrhenius and Bhatia model. The model predicts that the total surface initially increases and goes through a maximum and then decreases again. The good agreement with the experimental reaction rate is with regard to the temperature as well as to the oxidized mass dependence as documented by figs 9 and $\underline{10}$. Only the second phase of the rapid increasing reaction rate is not reconstructed accurately. However, the Arrhenius and Bhatia model seem best for reconstructing and 
predicting the regeneration. Using it can lead to quite accurate predictions of the duration of regeneration as well as of the entire oxidized particle mass.

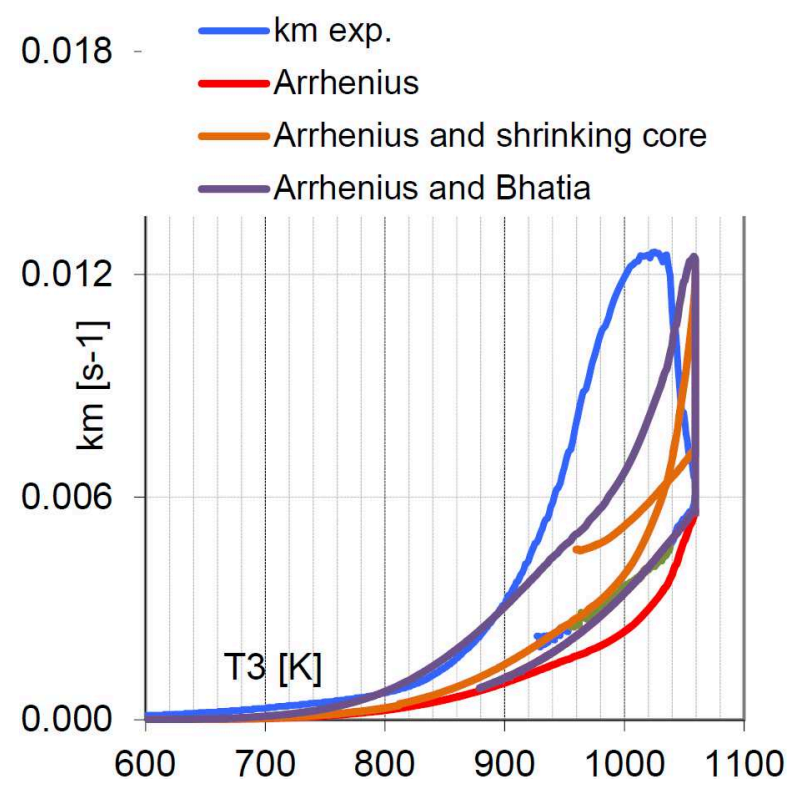

Figure 9. Experimental and modelled pseudo-first order reaction rate coefficient as a function of temperature.

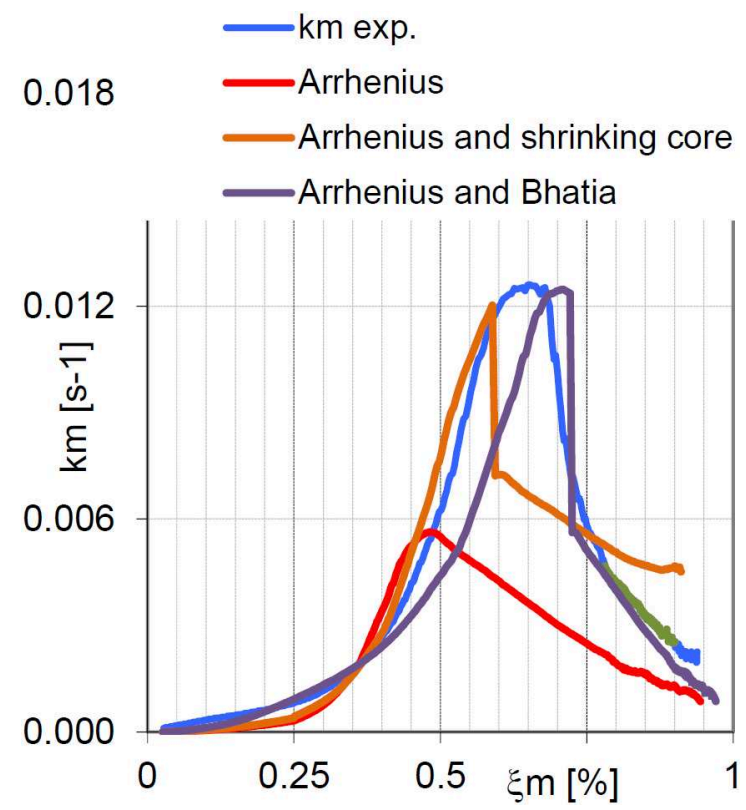

Figure 10. Experimental and modelled pseudo-first order reaction rate coefficient as a function of particle mass conversion (peripheral segment).

\section{Comparison of the Regeneration Behavior of Peripheral and Central DPF Segments.}

All peripheral segments tested had similar behavior characterized by a prolonged second phase reaching of the maximal temperature of $1062 \mathrm{~K}$ (average over all peripheral segments) at $\xi_{\mathrm{m}}=71 \%$ and the maximal pseudo first-order reaction rate of $\mathrm{k}_{\mathrm{m}}=0.013 \mathrm{~s}-1$, as summarized in Table 1 . Table 1 features also the associated standard deviations. The average activation energy obtained was $78 \mathrm{~kJ} / \mathrm{mol}$. The obtained values for the pre-exponential factors have a significant uncertainty.
Table 1. Average regeneration data comparison of central and peripheral DPF segments.

\begin{tabular}{|l|l|l|l|l|l|}
\hline $\begin{array}{l}\text { Segment } \\
\text { location } \\
\text { in DPF }\end{array}$ & $\begin{array}{l}\mathrm{Tmax} \\
{[\mathrm{K}]}\end{array}$ & $\begin{array}{l}\xi_{\mathrm{m}, \text { at }} \\
\mathrm{T}_{\max } \\
{[\%]}\end{array}$ & $\mathrm{k}_{\mathrm{m}, \max }\left[\mathrm{s}^{-1}\right]$ & $\begin{array}{l}\mathrm{E}_{\mathrm{A}} \\
{[\mathrm{kJ} / \mathrm{mol}]}\end{array}$ & $\mathrm{A}$ \\
\hline Central & $1022 \pm 14$ & $55 \pm 6$ & $0.0079 \pm 0.003$ & $48 \pm 3$ & $5 \pm 2$ \\
\hline Periphery & $1062 \pm 70$ & $71 \pm 9$ & $0.013 \pm 0.002$ & $78 \pm 9$ & $\begin{array}{l}306 \pm \\
171\end{array}$ \\
\hline
\end{tabular}

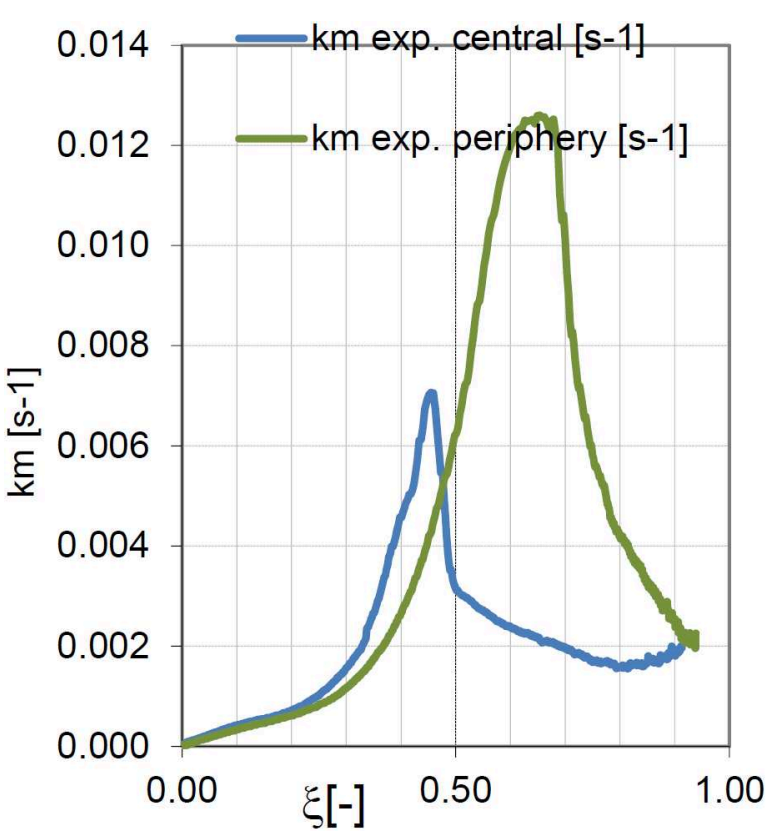

Figure 11. Comparison of experimental pseudo-first order reaction rate coefficient between a typical central and peripheral segment.

Central segments had a significantly different behavior as can be seen in Table 1. During regeneration they reached the peak temperature and peak reaction rates significantly earlier, at $\xi_{\mathrm{m}}=55 \%$, while the peak reaction rate values have also been significantly lower, $\mathrm{k}_{\mathrm{m}}=0.0079 \mathrm{~s}-1$. A comparison between two typical segments, one from the centre and one from the periphery are shown in figs. 11 and $\underline{12}$.

Fig. 12 shows that initially $\mathrm{t}<1000$ s (here $\mathrm{T} 3<500 \mathrm{~K}$ as can be seen in fig. 3 ) the change of mass of particles the peripheral segment is low but still detectable. In contrast, no change of mass could be detected in the central segment. This is a clear indication, that the particles have different consistency and or structure. After $t=1000$ s the particles in the central segment oxidize significantly faster. The trend is reversed after reaching the maximum rate (central segment at 1950s). This different oxidation behavior can only be attributed to different particle structures.

All segments have been loaded with particles under the same engine and exhaust gas conditions. The temperature of the exhaust gas entering the DPF during particle loading was low, 545K. Peripheral segments experienced lower temperatures, $30-40 \mathrm{~K}$ less.

Our hypothesis is that this distinctively different oxidation behavior can be attributed to this temperature difference: Particles in central segments experienced at the higher temperature level significant chemical reactions with $\mathrm{NO}_{2}$. 
This changed their structure rendering them easier to oxidize, thus the lower activation energy and the earlier oxidization. Particles from peripheral segments, at the lower temperatures, had almost no reactions with $\mathrm{NO}_{2}$.

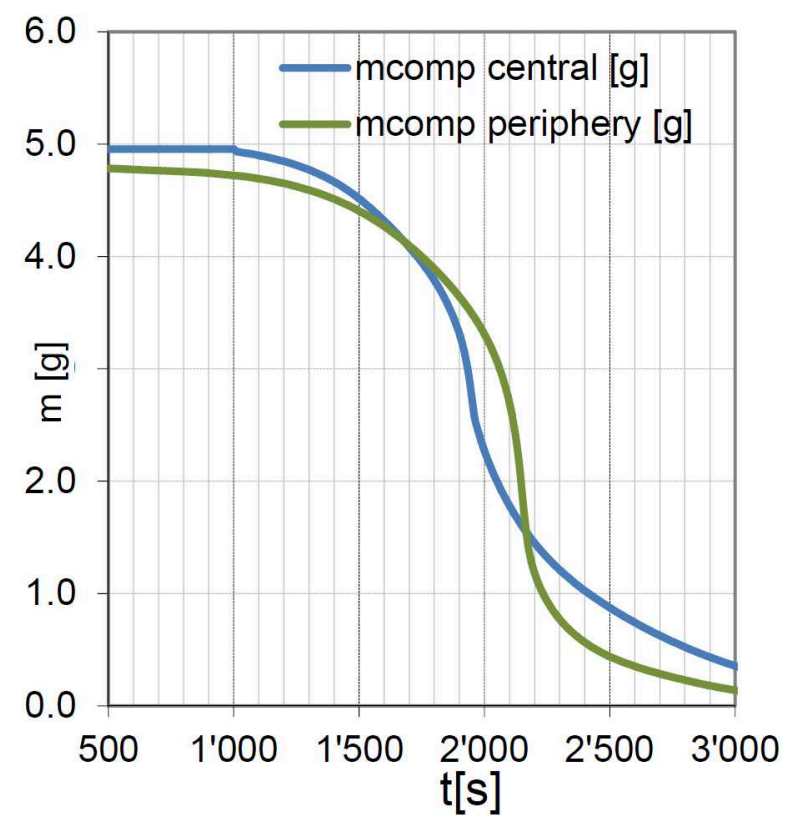

Figure 12. Comparison of particle oxidationover time between a typical central and peripheral segment.

\section{— km exp. central [s-1]}

-Arrhenius km [s-1]

Arrhenius and shrinking core model km [s-1]

-Arrhenius and Bhatia model km [s-1]

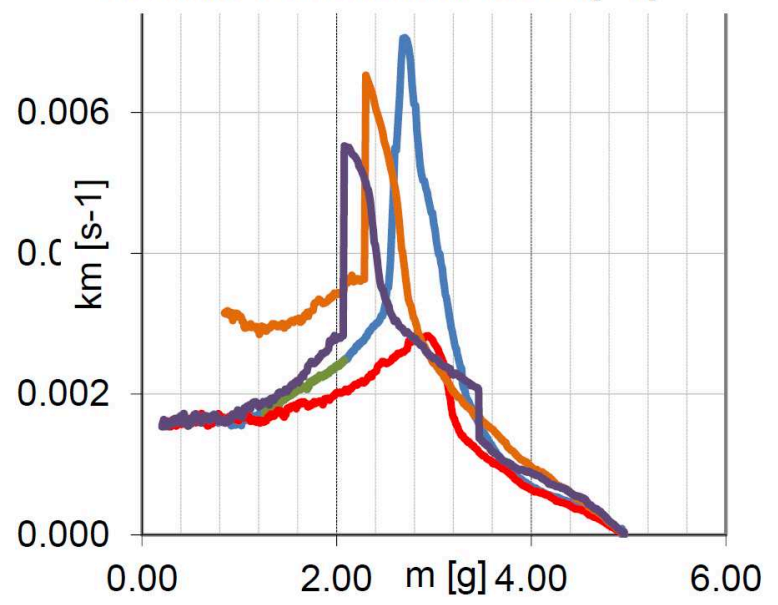

Figure 13. Experimental and modelled pseudo-first order reaction rate coefficient as a function of particle mass in the segment.

The regeneration reconstruction with the proposed models of a central segment gives an additional insight. Once again the "simple Arrhenius" model is not able to predict the second phase accurately. But neither is the Bhatia and Perlmutter model. Here the parameters that can be adjusted ( $\psi$ and $\mathrm{S}_{0}$ in Eq. 4 ) cannot predict the location and the magnitude of the maximum correctly. Best approximation is given by the shrinking core model.

\section{Comparison of the Regeneration Behavior of Peripheral DPF Segments with Feeding Gases Having Low Oxygen and Water Vapor.}

A limited number of peripheral segments have been regenerated on the test rig with lower oxygen content as well as with lower oxygen content and water vapor.

Interestingly the behavior was very similar to the other peripheral segments, i.e. some particulate oxidation in the first phase followed by a long second phase reaching a temperature and reaction rate maximum at around $\xi_{\mathrm{m}}=71 \%$. The peak values of the reaction rate and temperature have been significantly different. The gradient of the reaction rate over temperature has been significantly higher. The activation energy as well as the pre-exponential factors increased significantly.

Table 2. Average regeneration data comparison of peripheral DPF segments with different feed gas composition

\begin{tabular}{|l|l|l|l|l|l|}
\hline $\begin{array}{l}\text { Feedgas } \\
\text { composition }\end{array}$ & $\begin{array}{l}\text { Tmax } \\
{[\mathrm{K}]}\end{array}$ & $\begin{array}{l}\xi_{\mathrm{m}, \text { at }} \\
\mathrm{T}_{\max } \\
{[\%]}\end{array}$ & $\mathrm{k}_{\mathrm{m}, \max }\left[\mathrm{s}^{-1}\right]$ & $\begin{array}{l}\mathrm{E}_{\mathrm{A}} \\
{[\mathrm{kJ} / \mathrm{mol}]}\end{array}$ & $\mathrm{A}$ \\
\hline $\begin{array}{l}21 \% \mathrm{O}_{2}, \\
0 \% \mathrm{H}_{2} \mathrm{O}\end{array}$ & 1062 & 71 & 0.013 & 78 & 306 \\
\hline $\begin{array}{l}8 \% \mathrm{O}_{2}, \\
0 \% \mathrm{H}_{2} \mathrm{O}\end{array}$ & 1008 & 70 & 0.0063 & 160 & $210^{7}$ \\
\hline $\begin{array}{l}8 \% \mathrm{O}_{2}, \\
10 \% \mathrm{H}_{2} \mathrm{O}\end{array}$ & 961 & 70 & 0.0036 & 96 & 8000 \\
\hline
\end{tabular}

As summarized by Table 2, a lower oxygen concentration in the feedgas, results in lower peak temperature and lower peak reaction rate. The activation energy, as well as the pre-exponential factor increase significantly. Adding water vapor in the feedgas decreases the peak temperatures as well as the peak reaction rates even further. The activation energy and the pre-exponential factors, are lower than without water and closer to the values with $21 \%$ oxygen.

$\longrightarrow \mathrm{km} \exp$.

Arrhenius km [s-1]

Arrhenius and shrinking core model km [s-1]

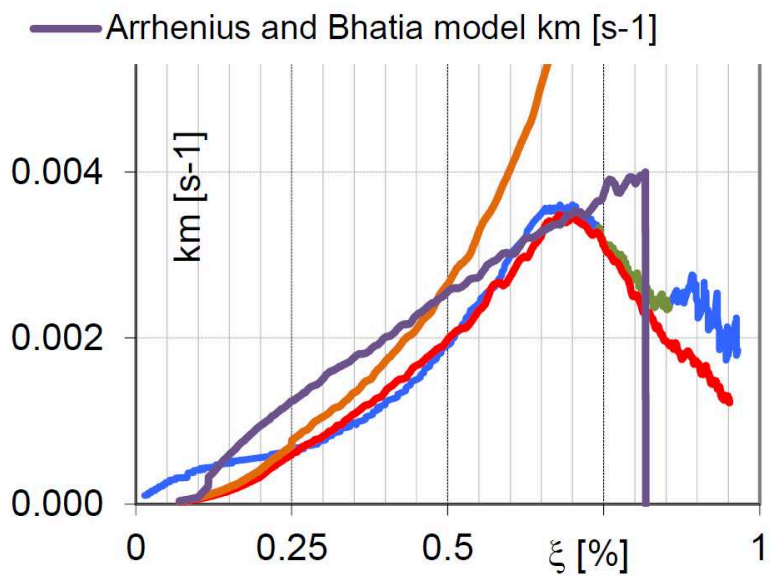

Figure 14. Experimental and modelled pseudo-first order reaction rate coefficient as a function of particle mass conversion for a peripheral segment with feedgas with low oxygen concentration and water vapor. 
Interestingly, the best approach for reconstructing these regenerations has been the "simple Arrhenius". Apart from the first and the last phase, the "simple Arrhenius" could reconstruct the regeneration remarkably well. The Bhatia and Permutter model lead also to acceptable approximations, while the shrinking core model was not able to lead to an acceptable approximation.

\section{Summary/Conclusions}

In this work, Diesel Particulate Filters (DPFs), have been loaded with particles of the exhaust of a small heavy duty truck operated on a chassis dynamometer under defined conditions. Engine and exhaust gas conditions during loading have been identical during all particulate loading procedures having a mean exhaust gas temperature of $540 \mathrm{~K}$. The dismantled DPFs have then been fragmented to their constituting segments. Each segment has been regenerated in a specially build test rig by controlled gases fed into the segment with controlled temperature.

The regeneration of all segments was characterized by five clear distinguished phases:

- Initial phase $(\mathrm{T}<800 \mathrm{~K})$ with slow temperature increase and low oxidation rates, in good agreement with results from TPO experiments reported in the literature.

- The rapid oxidation phase $\left(800 \mathrm{~K}<\mathrm{T}<\mathrm{T}_{\text {max }}\right)$ where oxidation results in increased temperature and increased reaction area. Both effects are reinforcing each other.

- A sudden collapse of the reaction rate that can be explained only by a sudden collapse of the particle reaction area leading to significant lower oxidation rates.

- A phase where the oxidation rate is linearly depended from the temperature $\left(\mathrm{T}>\mathrm{T}_{\max }, \xi_{\mathrm{m}}\left(\mathrm{T}_{\max }\right)<\xi_{\mathrm{m}}<0.9\right)$.

- In the last phase, $\xi_{\mathrm{m}}>0.9$, the particle mass remaining for oxidization is small leading to rather unstable results.

All peripheral segments, which experienced some $30-40 \mathrm{~K}$ lower temperatures during the particulate loading phase, showed very similar particulate oxidation behavior (feedgas dry air with $21 \% \mathrm{O}_{2}$ and no water):

- During phase 1 small but significant particle oxidation $\left(\xi_{\mathrm{m}}=0.25\right.$, at the end of phase 1) indicating a significant portion of volatiles

- Prolonged Phase 2 reaching peak temperatures at $\xi_{\mathrm{m}}=0.71$ in average

- Activation energies of in average $78 \mathrm{~kJ} / \mathrm{mol}$

- A combined Arrhenius and Bhatia and Perlmutter model was best suited for reconstructing the entire regeneration

Particulates from central segments in contrast, experiencing higher temperatures during the particulate loading phase, showed significantly stronger oxidation behavior:

- During phase 1 almost insignificant particle oxidation $\left(\xi_{\mathrm{m}}=0.1\right.$, at the end of phase 1) indicating very low portion of volatiles

- Short phase 2 reaching peak temperatures at $\xi_{\mathrm{m}}=0.55$ in average

- Activation energies of in average $48 \mathrm{~kJ} / \mathrm{mol}$
- A combined Arrhenius shrinking core model was best suited for reconstructing the entire regeneration

The difference in the behavior can be attributed to differences in the particulate consistency and structure. Central segments had a higher temperature during the particulate loading phase on the chassis dynamometer and thus have experienced significant $\mathrm{NO}_{2}$-particulate interaction and oxidation. The particulates in these segments are more prone to oxidation. In contrast, peripheral segments had very low, if any, $\mathrm{NO}_{2}$-particulate interaction. This resulted in particulates with higher resistance to oxidation. This hypothesis will be confirmed by additional experiments in future work, varying the temperature during loading as well as in analysis of particle samples by HRTEM.

Regenerations of peripheral segments with lower oxygen and water vapor in the feedgas showed:

- Similar behavior like the other peripheral segments.

- Lower peak reaction rates and temperatures.

- The derived activation energy for the low oxygen regeneration $\left(8 \% \mathrm{O}_{2}\right)$ was $160 \mathrm{~kJ} / \mathrm{mol}$ while for low oxygen and water vapor regeneration $96 \mathrm{~kJ} / \mathrm{mol}$.

- The "simple Arrhenius" (no adjusting parameters) model was the best for approximating and reconstructing such regenerations.

\section{References}

1. Messerer A., Niessner R., Pöschl U., Comprehensive kinetic characterization of the oxidation and gasification of model and real diesel soot by nitrogen oxides and oxygen under engine exhaust conditions: Measurement, Langmuir Hinshelwood, and Arrhenius parameters Carbon 44, 307-324, 2006

2. Stanmore B.R., Brilhac J.F., Gilot P., The oxidation of soot: review of experiments, mechanisms and models, Carbon (39), 2247-2268, 2001

3. Neeft J.P.A., Xander Nijhuis T., Smakman E., Makkee M. and Moulijn J. A., Kinetics of the oxidation of diesel soot, Fuel 76, 1129-1136, 1997.

4. Bhatia and Perlmutter, AIChE Journal 26, 379, 1980.

5. Yezerets et al., Applied Catalysis B: Environmental 61 120-129, 2005

6. Yezerets, A., Currier, N., and Eadler, H., "Experimental Determination of the Kinetics of Diesel Soot Oxidation by $\mathrm{O} 2$ Modeling Consequences," SAE Technical Paper 2003-01-0833, 2003, doi:10.4271/2003-01-0833.

7. Liatiand Eggenschwiler P. Dimopoulos, Characterisation of particulate matter deposited in diesel particulate filters: visual and analytical approach in macro-, micro- and nano-scales, Combustion and Flame, 157 1658-1670, 2010

8. Liati A., Eggenschwiler Dimopoulos P., Müller Gubler E., Schreiber D., Aguirre M., Microscopic investigation of diesel ash particulate matter: a SEM and TEM study, Atmospheric Environment, 49, 391-402, 2012

9. Liati A., Eggenschwiler Dimopoulos P., Spiteri A., Vogel N., Microscopic investigation of soot and ash particulate matter derived from biofuel and diesel: Implications for the reactivity of soot, Journal of Nanoparticle Research, 14:1224, 2012 
10. Liati A., Eggenschwiler P. Dimopoulos, Schreiber D., Zelenay V., Ammann M., Variations in diesel soot reactivity along the exhaust after-treatment system, based on the morphology and nanostructure of primary soot particles, Combustion and Flame $160,671-681,2013$

11. Song J., Alam M., Boehmann A.L., Kim U., Examination of the oxidation behaviour of biodiesel soot, Comb. Flame, 146, 589604,2006

12. Vander Wal R.L., Yezerets A., Currier N.W., Kim D. H., Wang C. M., HRTEM Study of diesel Soot collected from Diesel Particulate Filters, Carbon 45, 70-77, 2007

13. van Setten B.A.A.L., Makkee M., Moulijn J.A., Science and Technology of Catalytic Diesel Particulate Filters, Catalysis Reviews, 43(4), 489-564, 2001

14. Yehliu K., Vander Wal R.L.. Armas O., Boehman A.L., Combustion and Flame 159, 3597-3606,2012

15. Jaramillo I. C., Gaddam C. K., Vander Wal R.L., Huang, C-H, Levinthal J. D., Lighty J. S., Soot Oxidation kinetics under pressurized conditions, Combustion and Flame, 161, 29512965, 2014

16. Chilumukuru, K., Arasappa, R., Johnson, J., and Naber, J., "An Experimental Study of Particulate Thermal Oxidation in a Catalyzed Filter During Active Regeneration," SAE Technical Paper 2009-01-1474, 2009, doi:10.4271/2009-01-1474.

17. Reyes S., Jensen K.F., Percollation concepts in Modelling of Gas-Solid Reactions: I. Application to Char Gasification in the Kinetic Regime. Chem Eng. Sci., 41, 333-343, 1986

18. Fiebig M., Schönen M., Grütering U., Pischinger S., Einflüsse motorischer Betriebsparameter auf die Reaktivität von Dieselruss, MTZ, 71, 524-531, 2010

19. Zouaoui N., Brilhac J. F., Mechati F., Jeguirim M., Djellouli B., Gilot P., J. Therm. Anal. Calorim. 102, 837-849, 2010

20. Konstandopoulos, A., Kostoglou, M., Lorentzou, S., Pagkoura, C. et al., "Soot Oxidation Kinetics in Diesel Particulate Filters," SAE Technical Paper 2007-01-1129, 2007, doi:10.4271/200701-1129.

21. Koltsakis G.C., Stamatelos A. M., Modes of Catalytic Regeneration in Diesel particulate Filters. Ind. Chem. Res., Vol 36, 4155-4165, 1997

22. Eggenschwiler, Dimopoulos P., Schreiber, D., and Liati, A., "Active Regeneration Characteristics in Diesel Particulate Filters (DPFs)," SAE Technical Paper 2011-24-0185, 2011, doi: 10.4271/2011-24-0185.

\section{Contact Information}

P. Dimopoulos Eggenschwiler, Dr. sc. techn. Leiter/Head Gruppe

Abgasnachbehandlung/Exhaustaftertreatment Group

Automotive Powertrain Systems Laboratory

Empa Swiss Federal Laboratories for Materials Science and Technology

Ueberlandstrasse $129 \mathrm{CH}-8600$ Duebendorf

Tel +41-58-765 4337

Fax +41-58-765 4041

panayotis.dimopoulos@empa.ch

www.empa.ch 


\section{APPENDIX}

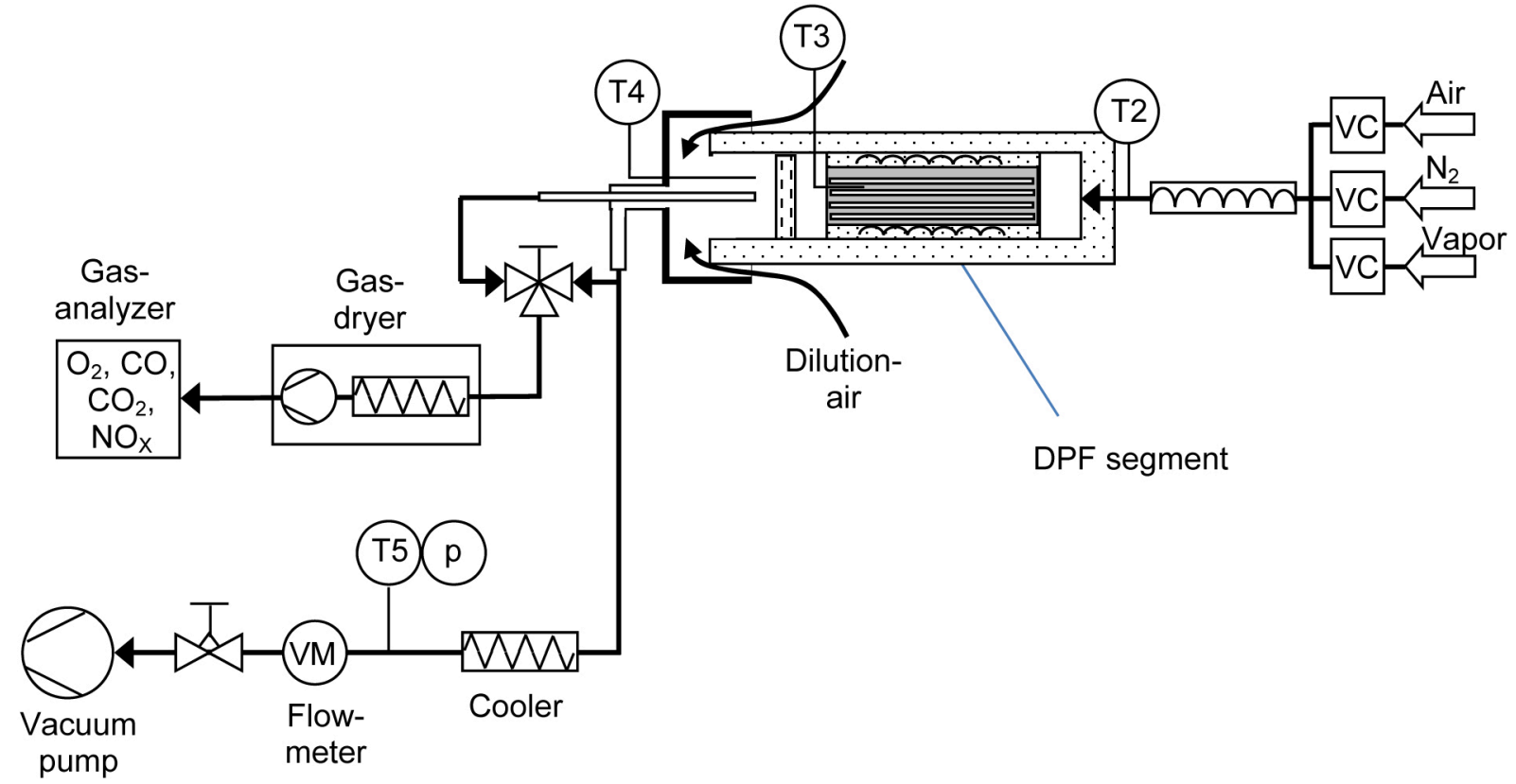

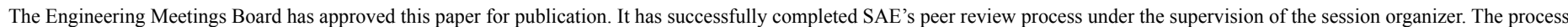
requires a minimum of three (3) reviews by industry experts.

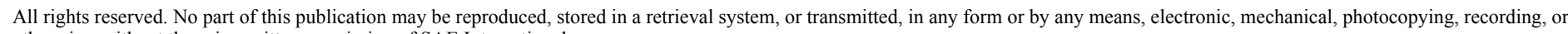
otherwise, without the prior written permission of SAE International.

Positions and opinions advanced in this paper are those of the author(s) and not necessarily those of SAE International. The author is solely responsible for the content of the paper.

ISSN 0148-7191

http://papers.sae.org/2015-24-2516 